\title{
Efficient oxygen reduction reaction by a highly porous, nitrogen-doped carbon sphere electrocatalyst through space confinement effect in nanopores
}

\author{
Zheyang $\mathrm{MO}^{a, b, \dagger}$, Weiyi $\mathrm{YANG}^{c, \dagger}$, Shuang $\mathrm{GAO}^{c}$, Jian $\mathrm{Ku} \mathrm{SHANG}^{b}$, \\ Yajun DING ${ }^{a, b}$, Wuzhu SUN ${ }^{d}$, Qi LI ${ }^{c, *}$ \\ ${ }^{a}$ School of Materials Science and Engineering, University of Science and \\ Technology of China, Shenyang 110016, China \\ ${ }^{b}$ Shenyang National Laboratory for Materials Science, Institute of Metal Research, \\ Chinese Academy of Sciences, Shenyang 110016, China \\ ${ }^{c}$ Key Laboratory of Advanced Technologies of Materials (Ministry of Education), School of Materials \\ Science and Engineering, Southwest Jiaotong University, Chengdu 610031, China \\ ${ }^{d}$ School of Materials Science and Engineering, Shandong University of Technology, Zibo 255000, China
}

Received: October 24, 2020; Revised: January 29, 2021; Accepted: February 13, 2021

(C) The Author(s) 2021.

\begin{abstract}
A highly porous nitrogen-doped carbon sphere (NPC) electrocatalyst was prepared through the carbonization of biomass carbon spheres mixed with urea and zinc chloride in $\mathrm{N}_{2}$ atmosphere. The sample carbonized at $1000{ }^{\circ} \mathrm{C}$ demonstrates a superior oxygen reduction reaction (ORR) performance over the $\mathrm{Pt} / \mathrm{C}$ electrocatalyst, while its contents of pyridinic nitrogen and graphitic nitrogen are the lowest among samples synthesized at the same or lower carbonization temperatures. This unusual result is explained by a space confinement effect from the microporous and mesoporous structures in the microflakes, which induces the further reduction of peroxide ions or other oxygen species produced in the first step reduction to water to have the preferred overall four electron reduction ORR process. This work demonstrates that in addition to the amount or species of its active sites, the space confinement can be a new approach to enhance the ORR performance of precious-metal-free, nitrogen-doped carbon electrocatalysts.
\end{abstract}

Keywords: precious-metal-free electrocatalyst; biomass resource; space confinement effect; $2 \mathrm{e}+2 \mathrm{e}$ pathway; oxygen reduction reaction (ORR)

\section{Introduction}

Fossil fuel is unrenewable and generating pollutions to

$\uparrow$ Zheyang Mo and Weiyi Yang contributed equally to this work.

* Corresponding author.

E-mail: qiliuiuc@outlook.com the environment every day. Thus, a clean energy solution is now being pursued actively all around the world in order to solve both the energy and environment problems now faced by human beings [1]. Among various approaches proposed, fuel cell is especially promising for power systems used in vehicles [2]. But the fuel cell performance is still limited by its slow 
kinetics of oxygen reduction reaction (ORR) on cathode [3]. Platinum-based electrocatalysts currently demonstrate the best ORR activity and are commercially available [4]. However, their high cost, poor methanol tolerance, and relatively low stability have prevented the large scale applications of fuel cells. Thus, the development of precious-metal-free (PGM-free) electrocatalysts of low cost with comparable or even better ORR performance than Pt-based electrocatalysts could overcome these difficulties $[5,6]$ allowing widespread applications of fuel cells [7,8] and metal-air batteries [9-11].

Nitrogen-doped carbon electrocatalysts are attracting more and more research interests as an important type of PGM-free electrocatalysts for ORR [12-18] since the first report by Dai's group in 2009 [19] that nitrogen-doped carbon nanotubes catalyzed oxygen reduction reaction with an excellent performance without metal element. It is now generally recognized that certain kinds of nitrogen species serve as active sites in these nitrogen-doped carbon electrocatalysts, and their catalytic performances are usually correlated with the type and the amount/density of these active sites [20,21]. Most reports in literature suggest that pyridinic nitrogen is the dominant active site for ORR $[22,23]$ while some other reports suggest that graphitic nitrogen (or quaternary nitrogen) is the main active site for ORR [24-26]. Beyond these specific nitrogen species, carbon defects [13,27] and carbon-anchored metal atoms (such as remaining $\mathrm{Zn}$ atoms $[28,29]$ ) are also credited with the ORR performance enhancement.

Recently, an interesting space confinement effect had been found in electrochemical carbon dioxide reduction (ECRR) for effective control of the product selectivity [30-34], which enhance catalytic reactions through the confinement of reactants or intermediates in a limited space. For example, Sargent's group [30] designed and synthesized a series of geometry tunable $\mathrm{Cu}$ nanocavities with various open angles, and attributed the observed $\mathrm{C} 3$ product promotion to the nanoconfinement effect on $\mathrm{C} 2$ intermediate through finite-element simulation and control experiments. For ORR, the product selectivity is also an important issue [35-37], in that the four electron reduction of oxygen to water is preferred for the fuel cell application over the two electron reduction of oxygen to hydrogen peroxide [35-37]. Since a highly porous structure in nitrogen-doped carbon electrocatalysts could potentially possess the space confinement effect, it could serve as an unexplored alternative approach to optimize the overall ORR performance of electrocatalysts.

Various approaches could create pores in carbon structures, including silica etching templating $[34,38]$ high-temperature removable templating [39], selfassembly [40], and porogen addition [41,42]. As an easily available metal with low boiling point, zinc could be thermally removed under $\sim 907{ }^{\circ} \mathrm{C}$ [43]. Thus, pores could be created in carbon structures to enhance various technical performances by proper carbonization treatment in a reductive environment via $\mathrm{Zn}$ evaporation once zinc species were induced into the precursor system [44-47]. In this work, a highly porous, nitrogendoped carbon sphere electrocatalyst was synthesized through a two-step process. First, biomass carbon spheres were synthesized from the hydrothermal treatment of glucose solution. They were then mixed with urea and zinc chloride, and carbonized at high temperatures in $\mathrm{N}_{2}$ atmosphere, resulting in a highly porous, nitrogen-doped carbon sphere. The sample carbonized at $1000{ }^{\circ} \mathrm{C}$ (NPC-1000) demonstrated a superior ORR performance over the commercial $\mathrm{Pt} / \mathrm{C}$ electrocatalyst, even though its pyridinic nitrogen and graphitic nitrogen contents were the lowest among the samples prepared at the same and lower carbonization temperatures. This unusual result suggested that more active sites did not always ensure a better ORR performance for electrocatalysts; instead, a space confinement effect on the ORR performance occurred in medium-sized pores $(\sim 1-10 \mathrm{~nm})$ and fine pores $(<1 \mathrm{~nm})$ in microflakes of NPC-1000 electrocatalyst. The effect is beneficial to the preferred overall four electron reduction ORR process by inducing the further reduction of peroxide ions or other oxygen species produced in the first step reduction to water. Thus, this work provides a novel approach of space confinement to enhance the ORR performance of low-cost, PGM-free nitrogen-doped carbon electrocatalysts, which may be extended in various novel catalyst designs to enhance their performances for technical applications.

\section{Experimental section}

\section{1 Materials}

All chemicals used were analytical purity and used without further purification. De-ionized (DI) water with a resistivity of $18.25 \mathrm{M} \Omega \cdot \mathrm{cm}^{-2}$ was also used in experiments. 


\section{2 Preparation of Glu-180 sample}

$80 \mathrm{~mL}$ glucose solution $(0.3 \mathrm{M})$ was first put into a $100 \mathrm{~mL}$ Teflon autoclave, and then heated at $180{ }^{\circ} \mathrm{C}$ for $10 \mathrm{~h}$ in an oven. Following the hydrothermal reaction, the product was collected by centrifugation, washed with deionized water, and finally dried in oven at $60{ }^{\circ} \mathrm{C}$ overnight.

\section{3 Preparation of NPC-t samples}

Glu-180 ( $\sim 0.5 \mathrm{~g})$ and urea were mixed at a mass ratio of 1:10, and then zinc chloride powder (mass ratio to Glu-180 equals 1:2) was added into the mixture. The mixture was ground by pestle milling for $30 \mathrm{~min}$, before the relatively homogenous mixture was calcined at $1000{ }^{\circ} \mathrm{C}$ for $2 \mathrm{~h}$ in a continuously flowing nitrogen atmosphere to form NPC-1000 sample. NPC-300, NPC-800, and NPC-900 samples were synthesized with the same method as NPC-1000 sample, except that their calcination temperatures were 300,800 , and $900{ }^{\circ} \mathrm{C}$, respectively. No product could be obtained when the calcination temperature was $1100{ }^{\circ} \mathrm{C}$. For comparison purpose, $\mathrm{NC}-1000$ sample was also prepared by the same method as NPC-1000 sample only without the addition of zinc sources.

\section{4 Sample characterization}

SEM (Zeiss Supra 55, Germany), TEM (JEOL 2010, Japan), and XPS (ESCALAB250, USA) analyses were used to examine the morphology and chemical composition of samples, while X-ray diffraction (XRD, Bruker D8 ADVANCE, USA) was used for structural analysis. The BET specific surface area was measured on an ASAP 2460 (Micromeritics, USA), and pore size distribution (PSD) was obtained through nonlocal density functional theory model (NLDFT) [48]. Raman spectra were recorded on a LabRAM HR800 (Horiba, Japan) with a $532 \mathrm{~nm}$ laser source. Thermogravimetric analysis (TGA, STA 449 C, NETZSCH, Germany) was conducted to analyze the thermal stability of the precursors in Ar atmosphere from room temperature to $1000{ }^{\circ} \mathrm{C}$ at a heating rate of $10{ }^{\circ} \mathrm{C} \cdot \mathrm{min}^{-1}$. $\mathrm{Zn}$ contents in samples were obtained by ICP-OES measurement (Agilent 725 ICP-OES, Santa Clara, USA).

\section{5 Electrochemical tests}

Working electrodes were prepared by coating glassy carbon rods $(D=3 \mathrm{~mm})$ with electrocatalyst solutions, made by first dispersing samples ( $4 \mathrm{mg}$ ) in a solvent mixture of $5 \mathrm{wt} \%$ Nafion solution $(0.1 \mathrm{~mL})$ and ethanol $(0.9 \mathrm{~mL})$, respectively, followed by sonication of $1.0 \mathrm{~h}$ to form relatively homogeneous suspensions. Then, $4 \mu \mathrm{L}$ of the resulted suspension was pipetted onto a pre-polished glassy carbon electrode to form the coating. For comparison, a commercially available 20 $\mathrm{wt} \% \mathrm{Pt} / \mathrm{C}$ electrocatalyst (JM) was used to prepare $\mathrm{Pt} / \mathrm{C}$ electrode with the same process. Electrochemical measurements were performed on an electrochemical workstation (PGSTAT204, Metrohm, Switzerland) and an RRDE configuration (RRDE-3A, ALS Co., Japan) in a three-electrode cell system at room temperature. The working, reference, and counter electrodes were a glassy carbon rotating disk electrode loaded with electrocatalyst, an $\mathrm{Ag} / \mathrm{AgCl}(3.0 \mathrm{M} \mathrm{KCl})$ electrode, and a graphite rod, respectively. To ensure the measurement accuracy, the graphite rod was used as the counter electrode to replace the Pt wire commonly used in ORR to avoid the potential redeposition of Pt clusters onto non-noble-metal-based electrocatalysts. The cyclic voltammetry and linear sweep voltammetry were performed at scan rates of 50 and $10 \mathrm{mV} \cdot \mathrm{s}^{-1}$, respectively. All potential values were normalized to reversible hydrogen electrode (RHE) based on the equation of $E(\mathrm{RHE})=E(\mathrm{Ag} / \mathrm{AgCl})+0.1976 \mathrm{~V}+0.0591 \mathrm{~V} \times \mathrm{pH}$. The stability and methanol tolerance tests were conducted by chronoamperometric responses at a constant potential of $0.35 \mathrm{~V}$ vs. $\mathrm{Ag} / \mathrm{AgCl}$ for ORR. For the methanol tolerance test, $1 \mathrm{~mL}$ methanol was pipetted into the $80 \mathrm{~mL}$ $\mathrm{O}_{2}$ saturated $0.1 \mathrm{M} \mathrm{KOH}$ electrolyte after $\sim 200$ s since the start of measurements.

Electron transfer number $(n)$ was obtained from the slope of Koutecky-Levich (K-L) plots $\left(J^{-1}\right.$ vs. $\left.\omega^{-1 / 2}\right)$ through the $\mathrm{K}-\mathrm{L}$ equation [49-51]:

$$
\begin{gathered}
\frac{1}{|J|}=\frac{1}{\left|J_{\mathrm{K}}\right|}+\frac{1}{\left|J_{\mathrm{L}}\right|} \\
J_{\mathrm{L}}=0.62 n F A D^{2 / 3} v^{-1 / 6} \omega^{1 / 2} C_{\mathrm{o}}
\end{gathered}
$$

where $J, J_{\mathrm{K}}$, and $J_{\mathrm{L}}$ is the measured current, kinetic-limited current, and diffusion-limited current, respectively. The constant " 0.62 " was chosen because the rotation rate of RDE or RRDE $\omega$ is in $\mathrm{rad} \cdot \mathrm{s}^{-1}$ [50]. The symbols of $F, A, D, v$, and $C_{\mathrm{o}}$ in a fixed electrochemical system refer to the Faraday constant $\left(96485 \mathrm{C} \cdot \mathrm{mol}^{-1}\right)$, geometric area of the RDE or RRDE, diffusion coefficient of $\mathrm{O}_{2}$ at room temperature (1.9× $10^{-5} \mathrm{~cm}^{2} \cdot \mathrm{s}^{-1}$ ), kinematic viscosity of the electrolyte 
$\left(1.0 \times 10^{-2} \mathrm{~cm}^{2} \cdot \mathrm{s}^{-1}\right)$, and the saturated bulk concentration of $\mathrm{O}_{2}$ in electrolyte $\left(1.2 \times 10^{-3} \mathrm{~mol} \cdot \mathrm{L}^{-1}\right)$ [51]. For the Tafel analysis based on LSV curves, the kineticlimited current was mass-transport corrected according to the $\mathrm{K}-\mathrm{L}$ equation $\left(\left|J_{\mathrm{K}}\right|=\frac{|J|}{1-|J| /\left|J_{\mathrm{L}}\right|}\right)$ [50], and then the Tafel equation was applied [52]:

$$
\eta=a-b \log \left(\left|J_{\mathrm{K}}\right|\right)
$$

where $\eta$ and $b$ refer to overpotential and Tafel plot, respectively.

Rotating ring-disk electrode (RRDE) measurements were conducted on an electrochemical workstation (CHI 760E, CH Instrument, China) equipped with a three-electrode cell system and an RRDE configuration (AFMSRCE, Pine Research Instrument, USA) with a disk electrode (glassy carbon, $S_{\text {disk }}=0.2472 \mathrm{~cm}^{2}$ ) and a ring electrode ( $\mathrm{Pt}$ electrode, $S_{\text {ring }}=0.1859 \mathrm{~cm}^{2}$ ). The current was collected at $0.3 \mathrm{~V}$ vs. $\mathrm{Ag} / \mathrm{AgCl}$ with a rotation rate of $1600 \mathrm{rpm}$. The electron transfer number $n$ was calculated based on the disk and ring currents by $n=4 I_{\mathrm{d}} /\left(I_{\mathrm{d}}+I_{\mathrm{r}} / N\right)$, where $I_{\mathrm{d}}$ and $I_{\mathrm{r}}$ are the disk and ring currents, respectively, and $N$ is the current collection efficiency of the Pt ring (0.37) [53].

\section{6 Molecular dynamics simulation}

Molecular dynamics simulations were carried out with the code LAMMPS [54] and corresponding molecular motions were visualized with the code OVITO [55]. All simulations were conducted in the NVT ensemble with non-periodic boarder setting. Interatomic potentials were represented as the sum of short-range coulombic interaction between atoms of charge $q_{i}$ with cutoff $r_{\mathrm{c}}$ and a short-range Lennard-Jones (L-J) 6-12 interaction potential with cutoff $r_{\mathrm{LJ}}$, according to the formulas as follow:

$$
\begin{gathered}
E_{i j}^{\mathrm{C}}=\frac{C q_{i} q_{j}}{\epsilon r}, \quad \text { where } r<r_{\mathrm{c}} \\
E_{i j}^{\mathrm{LJ}}=4 \epsilon_{i j}\left[\left(\frac{\sigma_{i j}}{r}\right)^{12}-\left(\frac{\sigma_{i j}}{r}\right)^{6}\right], \quad \text { where } r<r_{\mathrm{LJ}} \\
E_{i j}=E_{i j}^{\mathrm{C}}+E_{i j}^{\mathrm{LJ}}
\end{gathered}
$$

where $C$ is an energy-conversion constant, $\epsilon$ is the dielectric constant, and $\epsilon_{i j}$ and $\sigma_{i j}$ were both fitted $\mathrm{L}-\mathrm{J}$ interaction coefficients. Bond stretching of $\mathrm{O}-\mathrm{H}$ and $\mathrm{O}-\mathrm{O}$, and bending interaction of $\mathrm{O}-\mathrm{O}-\mathrm{H}$ were all set to be harmonic, according to the formulas as follow:

$E=K_{\text {stretch }}\left(r-r_{0}\right)^{2}$, for bond stretching interaction (7)

$E=K_{\text {bend }}\left(\theta-\theta_{0}\right)^{2}$, for bond bending interaction

where $K, r_{0}$, and $\theta_{0}$ are energy coefficient, equilibrium bond distance, and equilibrium bond angle, respectively. To avoid possible charge induced instability of this system, $\mathrm{OOH}^{*}$ radical was used instead of peroxide ion $\left(\mathrm{OOH}^{-}\right)$to perform this simulation. For more details of the space confinement model, please refer to the Electronic Supplementary Material (ESM).

\section{Results and discussion}

\section{1 Structure and morphology of nitrogen-doped carbon electrocatalysts.}

Figure 1(a) shows the synthesis process of nitrogendoped carbon electrocatalysts (NPC- $t$ samples). First, biomass carbon spheres were prepared by a hydrothermal treatment of glucose solution. Then, carbon spheres were mixed with proper amounts of urea as the nitrogen source and zinc chloride as the porogenic agent, and then carbonized in inert gas atmosphere to achieve the final product. Figure 1(b) compares the XRD diffraction patterns of Glu-180 mixed with urea and zinc chloride before calcination, and after calcination at $300,800,900$, and $1000{ }^{\circ} \mathrm{C}$, respectively. Without calcination, the sample shows the urea crystal structure due to its dominant existence in the mixture. After calcination, the samples generally have the amorphous carbon structure as indicated by the wide peak ranging from $2 \theta$ of $\sim 10^{\circ}$ to $30^{\circ}$ in their XRD diffraction patterns. When the calcination temperature was $300{ }^{\circ} \mathrm{C}$, XRD diffraction peaks belonging to urea disappear completely due to the decomposition of urea, while two peaks belonging to $\mathrm{g}-\mathrm{C}_{3} \mathrm{~N}_{4}$ at $2 \theta \approx 11.5^{\circ}$ and $27.0^{\circ}$ can be clearly identified [51], indicating the formation of $\mathrm{g}-\mathrm{C}_{3} \mathrm{~N}_{4}$ due to the reaction of carbon and urea during the calcination. When calcination temperature increased to $800{ }^{\circ} \mathrm{C}$ and over, XRD diffraction peaks belonging to $\mathrm{g}-\mathrm{C}_{3} \mathrm{~N}_{4}$ largely decrease and finally disappear with the calcination temperature increase.

Figure $\mathrm{S} 1$ in the ESM shows TGA curves of Glu-180, Glu-180 mixed with urea, and Glu-180 mixed with both urea and zinc chloride, where the reaction between urea and carbon to form $\mathrm{g}-\mathrm{C}_{3} \mathrm{~N}_{4}$ begins at $\sim 200{ }^{\circ} \mathrm{C}$, and the decomposition of $\mathrm{g}-\mathrm{C}_{3} \mathrm{~N}_{4}$ begins at 

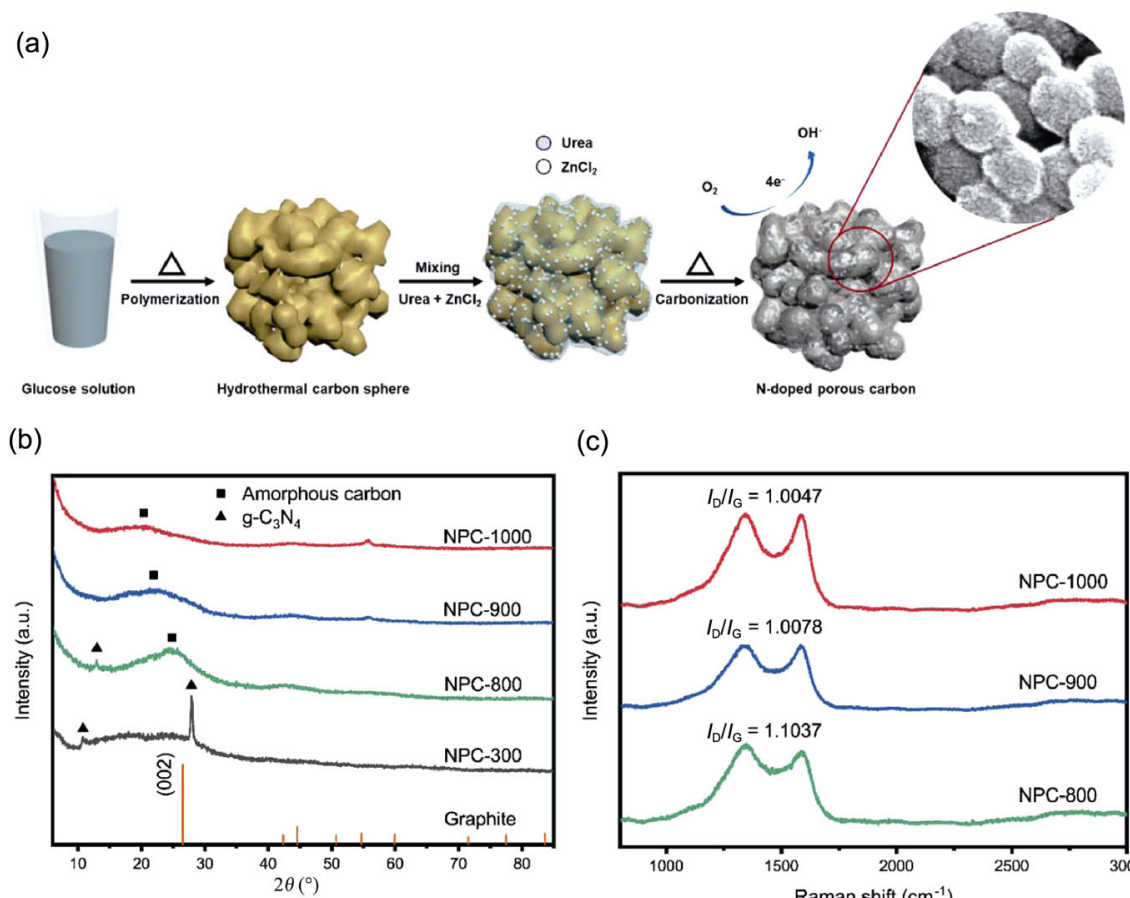

(c)

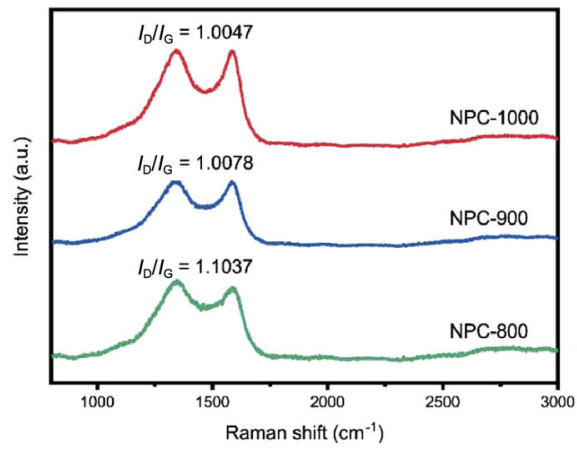

Fig. 1 (a) Schematic illustration of the synthesis process of highly porous, nitrogen-doped carbon sphere electrocatalysts. (b) XRD patterns and (c) Raman spectra of NPC- $t$ samples.

$\sim 250{ }^{\circ} \mathrm{C}$ and finishs mostly at $\sim 380{ }^{\circ} \mathrm{C}$. With the addition of zinc chloride, the decomposition of $\mathrm{g}-\mathrm{C}_{3} \mathrm{~N}_{4}$ is slightly depressed, which may be attributed to the melting of zinc chloride at the same time. Thus, TGA analysis is consistent with XRD analysis in that samples of NPC-800, NPC-900, and NPC-1000 are generally composed of $\mathrm{N}$-doped carbon spheres. Figure 1(c) compares the Raman spectra of obtained N-doped carbon spheres (NPC-800, NPC-900, and NPC-1000 samples). Their $I_{\mathrm{D}} / I_{\mathrm{G}}$ (the intensity ratio of D-band to G-band) values are all around 1.0, and their graphitization levels increase with the increase of the carbonization temperature as indicated by their slightly decreased $I_{\mathrm{D}} / I_{\mathrm{G}}$ values [56] and gradually narrowing $\mathrm{G}$ peak (suggesting enhanced ordering of bond angles at $\mathrm{sp}^{2}$ sites) [57].

The morphologies of these samples were investigated by both SEM and TEM observations. Figure 2(a) presents SEM images of NPC-800, NPC-900, and NPC-1000 samples, showing that they are generally composed of carbon spheres of $\sim 200-300 \mathrm{~nm}$ as expected. With the carbonization temperature increase, more and more microflakes occur between carbon spheres. Figure 2(b) shows TEM images of these samples, which verifies their spherical shape. With the carbonization temperature increase, more and more microflakes can be observed on the surface of carbon spheres, in consistence with SEM observations. The insets in Fig. 2(b) show their corresponding SAED patterns, which reveal the amorphous nature of the spheres. It should be noted that the diffraction rings of NPC-1000 sample are sharper than those of NPC-800 and NPC-900 samples, indicating that the higher crystallization temperature is beneficial to the crystallization. Figure 2(c) shows a high resolution TEM (HRTEM) image of the surface of a carbon sphere in NPC-1000 sample. It clearly demonstrates that substances with fingerprint-like patterns are on the sphere surface, which can be attributed to graphited microflakes produced by the high temperature carbonization.

BET analysis was used to investigate the microstructure nature of these nitrogen-doped carbon electrocatalysts. Figure 2(d) shows the $\mathrm{N}_{2}$ adsorption/ desorption isotherms of NPC-800, NPC-900, and NPC-1000 samples, all of which are type I curves with very steep slopes at low pressure. Thus, BET analysis indicates that a large amount of very small pores existed in all these samples. As the carbonization temperature increases from 800 to $1000{ }^{\circ} \mathrm{C}$, the BET specific surface area values increase from $\sim 965.18$ to $1786.41 \mathrm{~m}^{2} \cdot \mathrm{g}^{-1}$ (see Table S1 in the ESM). Figure 2(e) shows their pore size distribution (PSD) curves, which suggests that pores of three different size ranges exist in these samples. The large ones are from 10 to 


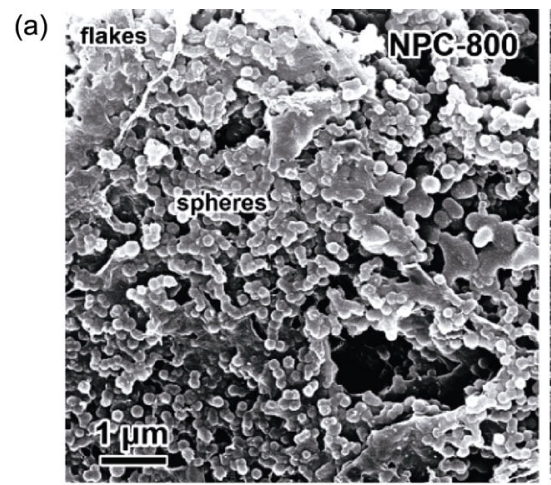

(b)
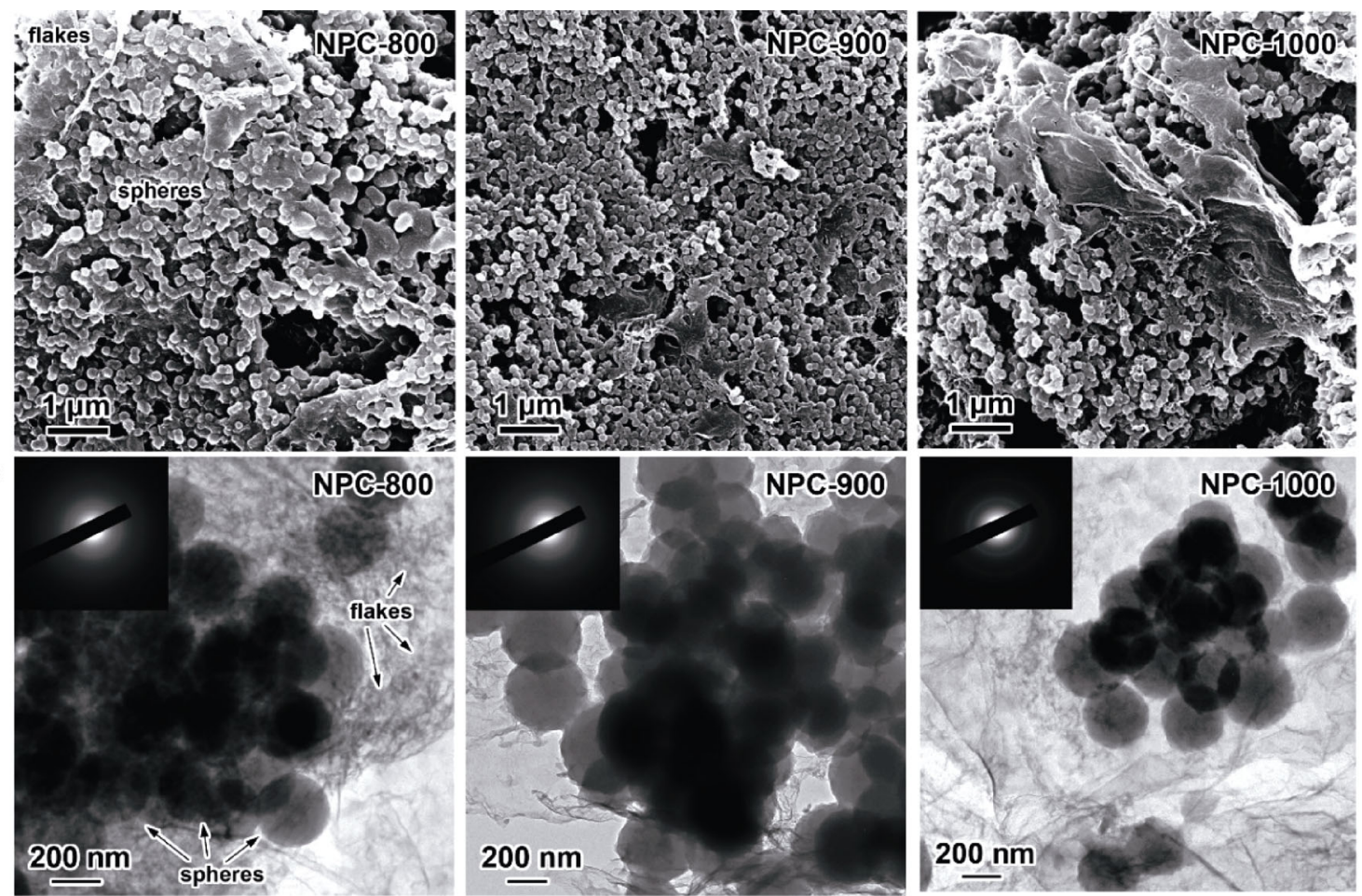

(c)
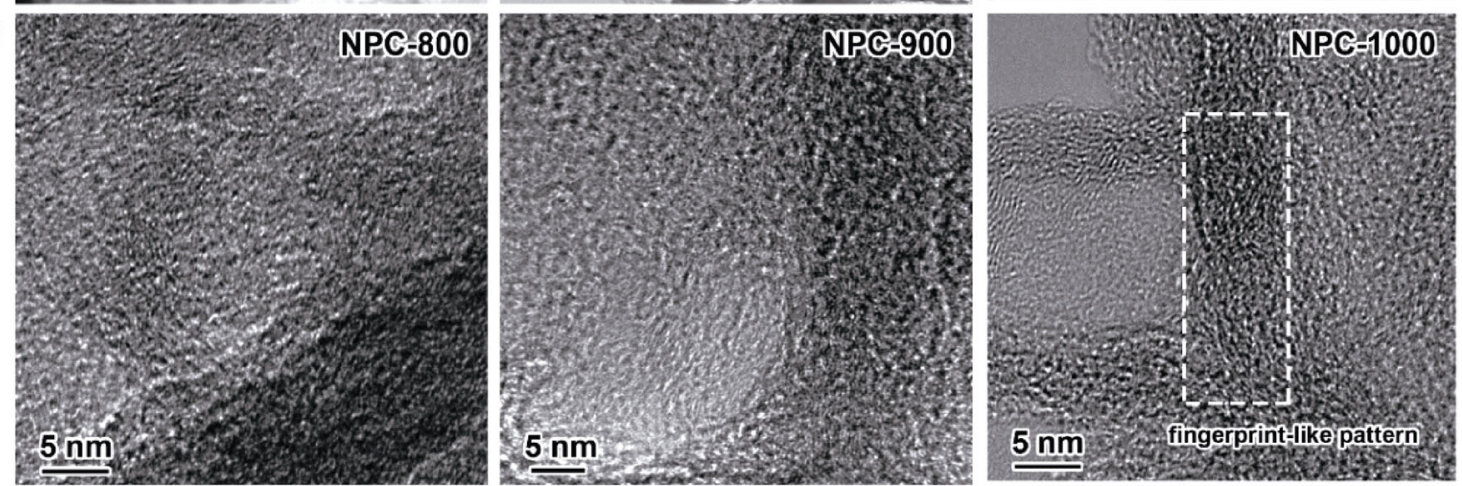

(d)
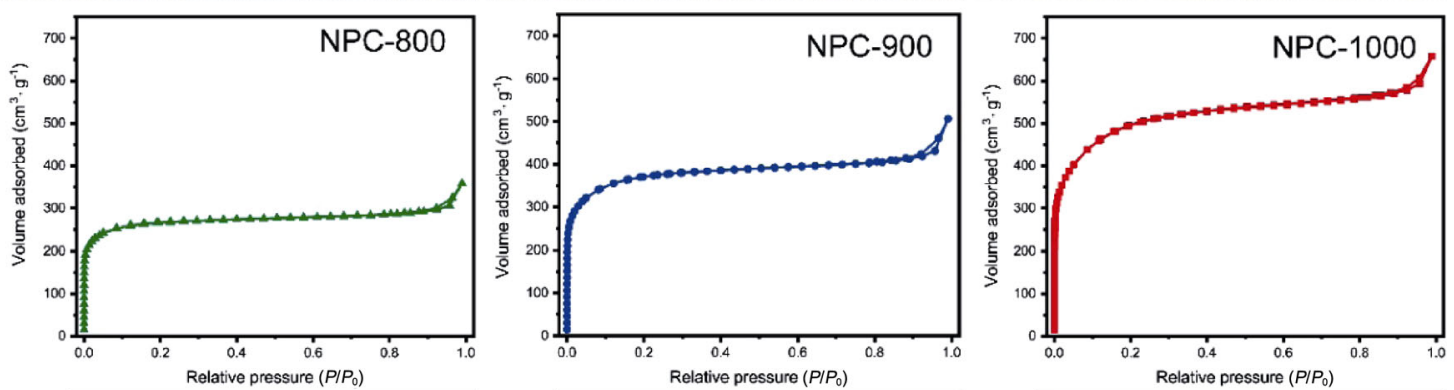

(e)
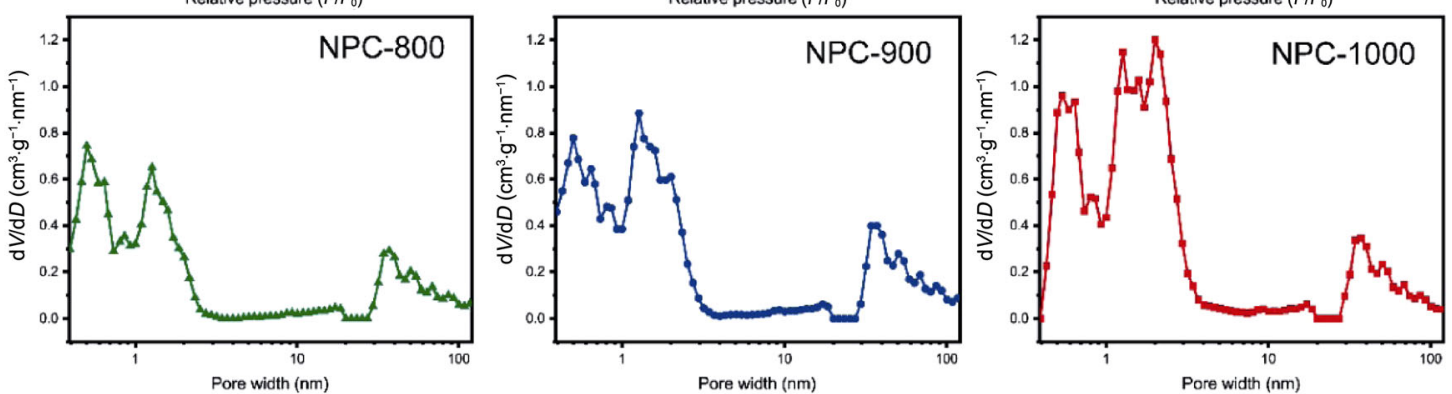

Fig. 2 (a) SEM images, (b) TEM images with corresponding SAED pattern, (c) HRTEM images, (d) $\mathrm{N}_{2}$ adsorption/desorption isotherms, and (e) pore size distributions (PSDs) of NPC-800, NPC-900, and NPC-1000 samples, respectively. 
$100 \mathrm{~nm}$, and no obvious difference exists among these samples. For fine pores $(<1 \mathrm{~nm})$ and medium-sized pores $(\sim 1-10 \mathrm{~nm})$, however, their amounts increase with the carbonization temperature, and a more significant increase of medium-sized pores can be observed. Figures S2(a) and S2(b) in the ESM compare the $\mathrm{N}_{2}$ adsorption/desorption isotherms and pore size distribution curves of NPC-1000 and NC-1000 (no zinc chloride) samples, respectively. Without zinc chloride additives, the BET specific surface area of NC-1000 sample $\left(\sim 1211.92 \mathrm{~m}^{2} \cdot \mathrm{g}^{-1}\right)$ is also smaller than that of NPC-1000 sample, and its amount of fine pores and especially medium-sized pores is also significantly lower than that of NPC-1000 sample.

Thus, the generation of large pores in these samples is apparently not dependent on the carbonization temperature (at or over $800{ }^{\circ} \mathrm{C}$ ) or the addition of zinc chloride, while they both had important effects on the generation of fine pores and medium-sized pores in particular. Due to the melting of zinc chloride at a low temperature of $\sim 290{ }^{\circ} \mathrm{C}$ [58], it can flow during the carbonization process and distribute uniformly in these carbon spheres. When the carbonization temperature is over $900{ }^{\circ} \mathrm{C}$, molten zinc chloride evaporates and subsequently creates large amounts of fine pores and medium-sized pores $[59,60]$, which largely increases the sample's surface area. Combined with their morphology differences, these analysis results suggest that large amount of fine pores and medium-sized pores in particular exist in microflakes of NPC-1000 sample, which results in its largest BET specific surface area among these samples compared.

\section{2 Chemical composition and active species of nitrogen-doped carbon electrocatalysts}

Figures S3(a)-S3(c) in the ESM show the EDS element mapping results of NPC-800, NPC-900, and NPC-1000 samples, respectively. It can be observed that $\mathrm{C}, \mathrm{N}$, and $\mathrm{Zn}$ elements are distributed uniformly in these samples. For NPC-800 sample, the existence of $\mathrm{Zn}$ is quite clear, while the $\mathrm{Zn}$ signal becomes weaker when the carbonization temperature increases to $900{ }^{\circ} \mathrm{C}$ and even unidentifiable after $1000{ }^{\circ} \mathrm{C}$ carbonization. XPS analysis was further used to provide semi-quantitative chemical composition information for these samples. Figures S4(a) and S4(b) in the ESM compare their XPS survey spectra and high resolution XPS scans over $\mathrm{Zn} 2 \mathrm{p}$ peaks, respectively, which also demonstrate the continuous decrease of $\mathrm{Zn}$ content in these samples.
These observations indicate that zinc chloride evaporates fast when the carbonization temperature increases to $900{ }^{\circ} \mathrm{C}$ and over, leaving behind a large amount of medium-sized pores and fine pores [59,60], consistent with BET analysis.

Figure 3(a) summarizes the contents of different elements in NPC-800, NPC-900, NPC-1000, and NC-1000 samples. With the carbonization temperature increases, the carbon content gradually increases due to the continuous carbonization process, while contents of other elements gradually decrease subsequently. Figures S5(a)-S5(d) in the ESM show the high resolution XPS scans over N 1s peak of NPC-800, NPC-900, NPC-1000, and NC-1000 samples, respectively, which clearly demonstrate that various types of $\mathrm{N}$ existed in these samples. Figure 3(b) summarizes the nitrogen contents of various types in NPC-800, NPC-900, and NPC-1000 samples, compared with that of NC-1000 sample without zinc chloride additives. As summarized in Table S1 in the ESM, the nitrogen contents are 5.89, 3.83, 1.81, and 2.36 at $\%$ for NPC-800, NPC-900, NPC-1000, and NC-1000 samples, respectively. With the increase of carbonization temperature, the total N content in NPC-800, NPC-900, and NPC-1000 samples gradually decreases. The addition of zinc chloride also causes the total $\mathrm{N}$ content decrease as demonstrated by the comparison between NPC-1000 and NC-1000 samples, which may be attributed to the fact that the evaporation of $\mathrm{Zn}$ could inevitably cause part of doped-N off the porous carbon substrate.

It is generally believed that graphitic-N or pyridinic-N provides active sites for oxygen reduction reaction in metal-free carbon-based catalysts [22-26]. Figure 3(b) compares the contents of different types of nitrogen species in these samples obtained from XPS analysis, and their values are summarized in Table S2 in the ESM. The graphitic-N contents in NPC-800, NPC-900, and NPC-1000 samples are 0.64, 1.08, and 0.83 at $\%$, respectively. A higher carbonization temperature of $900{ }^{\circ} \mathrm{C}$ favors the formation of the more stable graphitic-N than either pyridinic-N or pyrrolic-N than a lower carbonization temperature of $800{ }^{\circ} \mathrm{C}$, while the even higher carbonization temperature of $1000{ }^{\circ} \mathrm{C}$ causes the decrease of the total $\mathrm{N}$ content and subsequently lowers the graphitic-N content. The pyridinic-N and pyrrolic- $\mathrm{N}$ contents in these samples gradually decrease with the carbonization temperature increase, while their oxidized-N contents are generally constant at $\sim 0.2$ at $\%$. The zinc chloride addition 

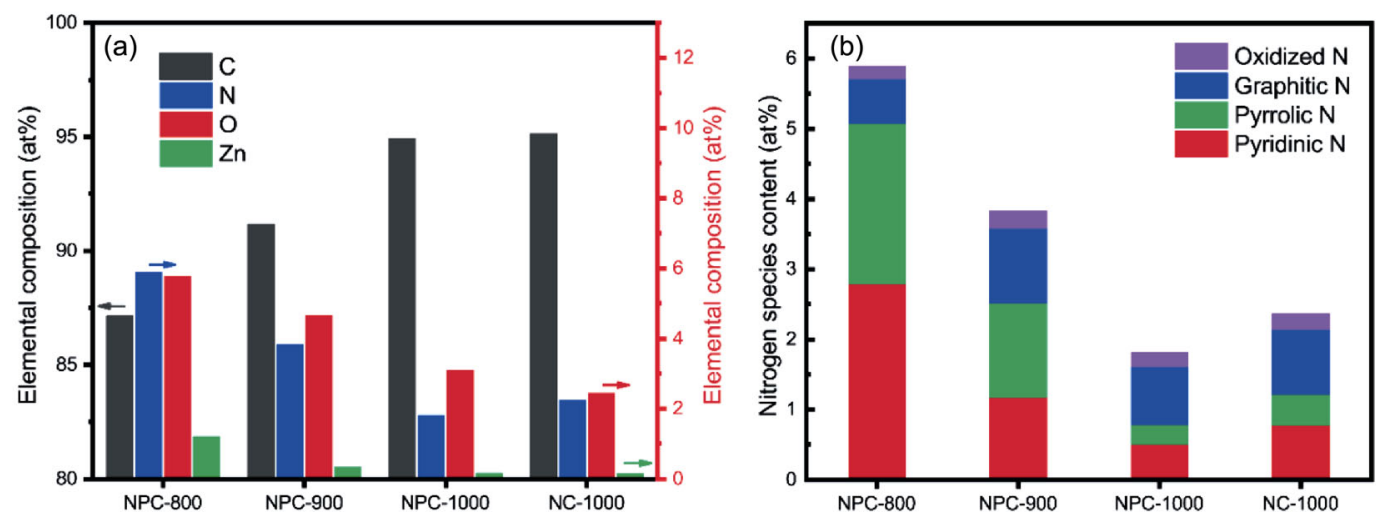

Fig. 3 XPS analysis of (a) contents of different elements and (b) nitrogen contents of various types in NPC-800, NPC-900, NPC-1000, and NC-1000 samples, respectively.

apparently does not affect the graphic-N or oxidized-N contents as demonstrated by the comparison between NPC-1000 and NC-1000 samples, while the pyridinic-N and pyrrolic-N contents are obviously lower in the NPC-1000 sample, indicating that the zinc chloride addition has an adverse effect on their contents. The combined graphitic-N and pyridinic-N contents are $\sim 3.43,2.26,1.34$, and 1.71 at $\%$ for NPC-800, NPC-900, NPC-1000, and NC-1000 samples, respectively.

\section{3 Electrocatalytic activity for ORR of nitrogen- doped carbon sphere electrocatalysts}

Surprisingly, the ORR performances of these nitrogendoped carbon sphere electrocatalysts are found to be opposite to their graphitic-N or pyridinic-N content sequence. As shown in Fig. 4(a), their cyclic voltammetry (CV) tests were first conducted in both $\mathrm{N}_{2-}$ and $\mathrm{O}_{2}$-saturated $0.1 \mathrm{M} \mathrm{KOH}$ electrolyte at the scan rate of $50 \mathrm{mV} \cdot \mathrm{s}^{-1}$, compared with that of the commercially available $\mathrm{Pt} / \mathrm{C}$ electrocatalyst $(20 \mathrm{wt} \% \mathrm{Pt})$. No redox peak can be found for either of them or the $\mathrm{Pt} / \mathrm{C}$ electrocatalyst in the inert $\mathrm{N}_{2}$-saturated $\mathrm{KOH}$ electrolyte, suggesting that ORR did not occur without the presence of $\mathrm{O}_{2}$. However, distinct ORR peaks appear for all NPC- $t$ samples in the $\mathrm{O}_{2}$-saturated $\mathrm{KOH}$ electrolyte, which are centered at $\sim 0.75 \mathrm{~V}$ with the peak current density of $\sim-1.65 \mathrm{~mA} \cdot \mathrm{cm}^{-2}, \sim 0.81 \mathrm{~V}$ with the peak current density of $\sim-1.86 \mathrm{~mA} \cdot \mathrm{cm}^{-2}$, and $\sim 0.83$ $\mathrm{V}$ with the peak current density of $\sim-3.04 \mathrm{~mA} \cdot \mathrm{cm}^{-2}$ for NPC-800, NPC-900, and NPC-1000 samples, respectively. For the $\mathrm{Pt} / \mathrm{C}$ electrocatalyst, the ORR peak occurs at $\sim 0.84 \mathrm{~V}$ with the peak current density of $\sim-2.02 \mathrm{~mA} \cdot \mathrm{cm}^{-2}$. Thus, the NPC-1000 sample can possess a comparable ORR activity to that of $\mathrm{Pt} / \mathrm{C}$, due to the close peak positions for both electrodes and an even higher peak current density for the NPC-1000 sample.

Figure 4(b) compares the linear scan voltammetry (LSV) curves of NPC-800, NPC-900, NPC-1000, $\mathrm{NC}-1000$, and $\mathrm{Pt} / \mathrm{C}$ samples in the $\mathrm{O}_{2}$-saturated $0.1 \mathrm{M}$ $\mathrm{KOH}$ electrolyte at a scan rate of $10 \mathrm{mV} \cdot \mathrm{s}^{-1}$ on the rotating disk electrode (RDE) measurement at a rotating speed of $1600 \mathrm{rpm}$. The intersection of two tangents drawn from the rising current part and the background current part was used to estimate the onset potential of ORR. The detailed LSV curve data is summarized in Table S3 in the ESM. The NPC-1000 sample has a more positive ORR onset potential $(0.925$ $\mathrm{V})$ and higher half-wave potential $(0.859 \mathrm{~V})$ than those of the $\mathrm{Pt} / \mathrm{C}$ electrocatalyst (ORR onset potential of $0.922 \mathrm{~V}$ and half-wave potential of $0.851 \mathrm{~V}$ ), and a very similar diffusion-limited current density $\left(5.0 \mathrm{~mA} \cdot \mathrm{cm}^{-2}\right.$ for NPC-1000 vs. $5.1 \mathrm{~mA} \cdot \mathrm{cm}^{-2}$ for the $\mathrm{Pt} / \mathrm{C}$ electrocatalyst). The comparisons clearly demonstrate that the NPC-1000 sample has a better or at least comparable ORR activity as that of $\mathrm{Pt} / \mathrm{C}$ electrocatalyst, while the ORR activities of NC-1000, NPC-800, and NPC-900 samples are lower than that of NPC-1000 sample although they had higher contents of graphitic-N and pyridinic-N. Table S4 in the ESM summarizes ORR performances of various metal-free electrocatalysts recently reported in literature [51,6167], indicating that NPC-1000 electrocatalyst can compete with these best metal-free catalysts recently reported.

For application purpose, a potential ORR electrocatalyst must have good long-term stability and tolerance to methanol crossover. Figure 4(c) compares the chronoamperometric responses $(i-t)$ of NPC-1000 and $\mathrm{Pt} / \mathrm{C}$ electrocatalysts measured in $\mathrm{O}_{2}$-saturated $0.1 \mathrm{M}$ 
(a)

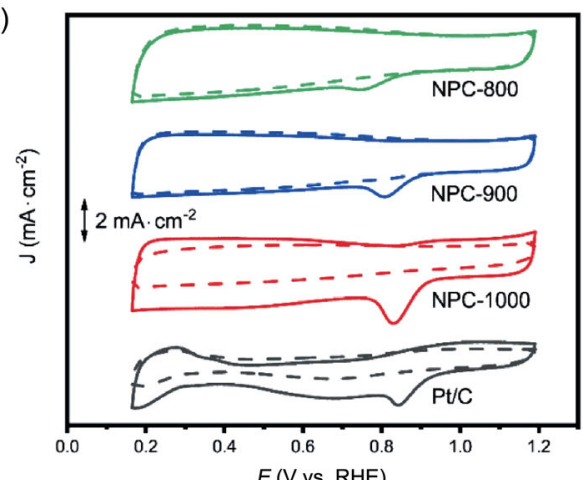

(c)

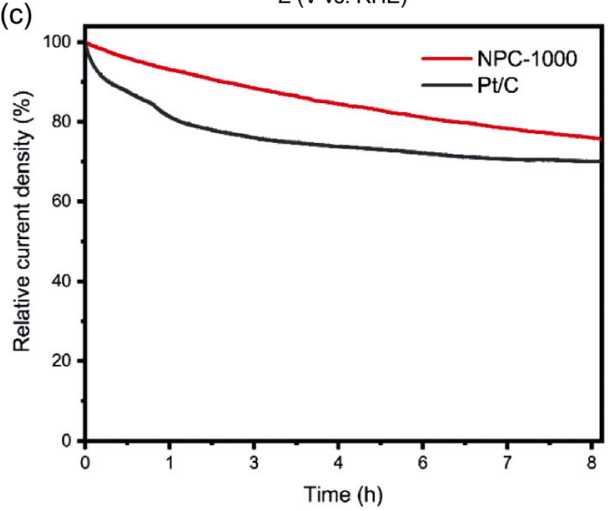

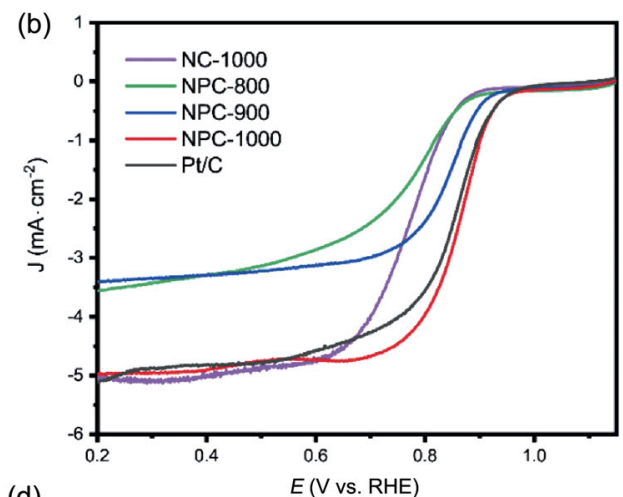

(d)

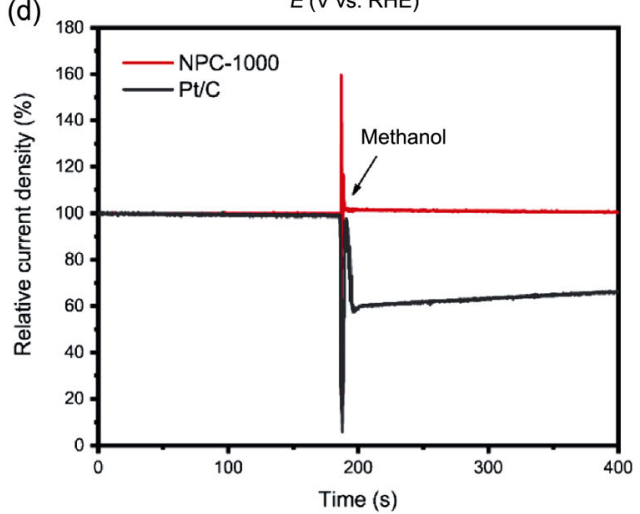

Fig. 4 (a) Cyclic voltammetry (CV) test curves of NPC-800, NPC-900, and NPC-1000 samples in both $\mathrm{N}_{2}$ (dash line) and $\mathrm{O}_{2}$-saturated (solid line) $0.1 \mathrm{M} \mathrm{KOH}$ electrolyte with the scan rate of $50 \mathrm{mV} \cdot \mathrm{s}^{-1}$, compared with that of the commercially available $\mathrm{Pt} / \mathrm{C}$ electrocatalyst $(20 \mathrm{wt} \% \mathrm{Pt}$ ). (b) Linear sweep voltammetry (LSV) curves of NPC-800, NPC-900, NPC-1000, $\mathrm{NC}-1000$, and $\mathrm{Pt} / \mathrm{C}$ samples in the $\mathrm{O}_{2}$-saturated $0.1 \mathrm{M} \mathrm{KOH}$ electrolyte at a scan rate of $10 \mathrm{mV} \cdot \mathrm{s}^{-1}$ on the rotating disk electrode (RDE) measurement at a rotating speed of $1600 \mathrm{rpm}$. (c) Chronoamperometric responses $(i-t)$ of NPC-1000 and Pt/C electrocatalysts measured in $\mathrm{O}_{2}$-saturated $0.1 \mathrm{M} \mathrm{KOH}$ solution at $0.35 \mathrm{~V}$ vs. $\mathrm{Ag} / \mathrm{AgCl}$ for $8 \mathrm{~h}$ with the rotation rate of $1600 \mathrm{rpm}$. (d) Chronoamperometric responses $(i-t)$ of NPC-1000 and Pt/C electrocatalysts measured in $\mathrm{O}_{2}$-saturated $0.1 \mathrm{M} \mathrm{KOH}$ solution at $0.35 \mathrm{~V}$ vs. $\mathrm{Ag} / \mathrm{AgCl}$ with the rotation rate of $1600 \mathrm{rpm}$. After the tests began for $200 \mathrm{~s}, 1 \mathrm{~mL}$ methanol was added into $80 \mathrm{~mL}$ electrolyte to stimulate methanol cross.

$\mathrm{KOH}$ solution at $0.35 \mathrm{~V}$ vs. $\mathrm{Ag} / \mathrm{AgCl}$ for $8 \mathrm{~h}$ with the rotation rate of $1600 \mathrm{rpm}$. It demonstrates clearly that the NPC-1000 electrocatalyst exhibits a much better long-term stability than the $\mathrm{Pt} / \mathrm{C}$ electrocatalyst within the whole operation time investigated. Figure 4(d) compares the chronoamperometric responses $(i-t)$ of NPC-1000 and Pt/C electrocatalysts measured in $\mathrm{O}_{2}$-saturated $0.1 \mathrm{M} \mathrm{KOH}$ solution at $0.35 \mathrm{~V}$ vs. $\mathrm{Ag} / \mathrm{AgCl}$ with the rotation rate of $1600 \mathrm{rpm}$. After the tests began for $\sim 200 \mathrm{~s}, 1 \mathrm{~mL}$ methanol was pipetted into $80 \mathrm{~mL}$ electrolyte to stimulate methanol cross. The NPC-1000 electrocatalyst demonstrates a steady ORR current, while the $\mathrm{Pt} / \mathrm{C}$ electrocatalyst has a sharp decrease of its ORR current right after the methanol addition. Thus, the NPC-1000 electrocatalyst has a satisfactory tolerance to methanol crossover, while the $\mathrm{Pt} / \mathrm{C}$ electrocatalyst does not. In this regard, the NPC-1000 catalyst has a particular advantage over the $\mathrm{Pt} / \mathrm{C}$ electrocatalyst because the direct methanol fuel cell (DMFC) is deemed a very promising power solution in the future [68-71].

\section{4 Origin of superior ORR performance of NPC-1000 electrocatalyst}

To investigate the origin of this inconsistency and the superior ORR performance of NPC-1000 sample, the ORR electron transfer kinetics of these NPC- $t$ electrocatalysts were investigated by measuring the linear sweep voltammetry curves of these samples at rotating speeds from 225 to $2025 \mathrm{rpm}$ in the $\mathrm{O}_{2}$-saturated $0.1 \mathrm{M} \mathrm{KOH}$ electrolyte. The corresponding KouteckyLevich $(\mathrm{K}-\mathrm{L})$ plots $\left(J^{1}\right.$ vs. $\left.\omega^{-1 / 2}\right)$ were derived from LSV curves. Figure 5(a) presents the linear sweep voltammetry curves of NPC-1000 sample at a series of rotating speeds and the inset image in Fig. 5(a) shows its corresponding $\mathrm{K}-\mathrm{L}$ plots, while results of the $\mathrm{Pt} / \mathrm{C}$, NPC-800, and NPC-900 electrocatalysts are shown in Figs. S6(a)-S6(f) in the ESM, respectively. By 

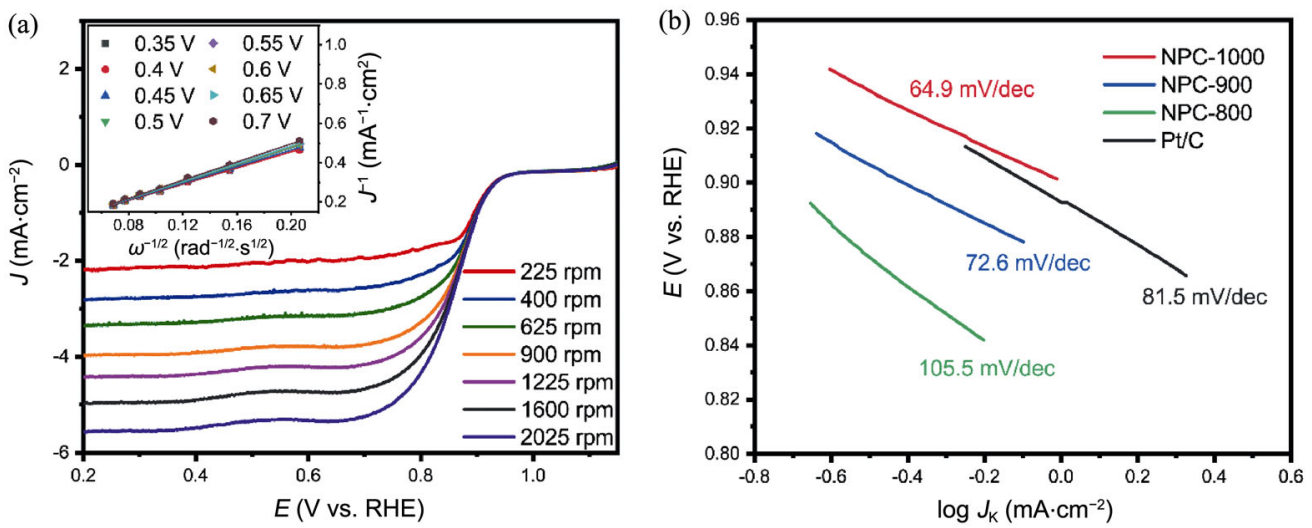

Fig. 5 (a) Linear sweep voltammetry curves of NPC-1000 sample at rotating speeds from 225 to 2025 rpm (note, the inset image shows their corresponding K-L plots). (b) Tafel slopes of NPC-800, NPC-900, NPC-1000, and Pt/C samples derived from the RDE measurements at $1600 \mathrm{rpm}$, respectively.

comparing these LSV curves, it can be found that the $\mathrm{K}-\mathrm{L}$ plots of NPC-1000 and $\mathrm{Pt} / \mathrm{C}$ electrocatalysts are very close at different potentials, while those of NPC800 and NPC-900 electrocatalysts are divergent at different potentials. Thus, the corresponding intercepts of negative potential of NPC-1000 and $\mathrm{Pt} / \mathrm{C}$ electrocatalysts are closer to zero than those of NPC- 800 and NPC-900 electrocatalysts, indicating larger kinetic currents and faster kinetic reactions [72,73]. According to the $\mathrm{K}-\mathrm{L}$ equation, the electron transfer numbers $(n)$ of NPC-800, NPC-900, NPC-1000, and Pt/C electrocatalysts can be determined by the slops of their $\mathrm{K}-\mathrm{L}$ plots as 1.6-2.0, 1.9-2.2, 4.0-4.2, and 3.6-4.0, respectively.

Due to the inaccuracy issue of bending $\mathrm{K}-\mathrm{L}$ plots to determine the electron transfer number from the decomposition of $\mathrm{H}_{2} \mathrm{O}_{2}$ [74], their electron transfer numbers were further examined by the rotating ring-disk electrode (RRDE) measurement. In this series of RRDE measurements, the catalyst loadings of NPC-800, NPC-900, and NPC-1000 electrocatalysts were $\sim 0.31,0.23$, and $0.16 \mathrm{mg} \cdot \mathrm{cm}^{-2}$, respectively, to make them to have the same surface area. Figure S7(a) in the ESM shows the LSV curves of NPC-800, NPC-900, and NPC-1000 samples, compared with the $\mathrm{Pt} / \mathrm{C}$ sample $\left(0.16 \mathrm{mg} \cdot \mathrm{cm}^{-2}\right)$ in the $\mathrm{O}_{2}$-saturated $0.1 \mathrm{M}$ $\mathrm{KOH}$ electrolyte at a scan rate of $10 \mathrm{mV} \cdot \mathrm{s}^{-1}$ and a rotating speed of $1600 \mathrm{rpm}$. The comparison demonstrates that the NPC-1000 sample has the best ORR performance among NPC- $t$ samples investigated, although they had the same surface area and the NPC-1000 sample had the lowest active-N species content. Thus, the result clearly shows that the largest specific surface area of the NPC-1000 sample among these NPC- $t$ samples is not the reason for its best ORR performance. Figure S7(b) in the ESM shows their electron transfer numbers obtained from RRDE measurements. The electron transfer numbers are 3.2-3.8, 3.2-3.9, 3.6-4.0, and 3.8-4.0 for NPC-800, NPC-900, NPC-1000, and Pt/C electrocatalysts, respectively. This analysis results suggest that NPC-800 and NPC-900 electrocatalysts have more undesirable two-electron transfer process in ORR, while NPC-1000 and Pt/C electrocatalysts have more desirable four-electron transfer process in ORR.

On the basis of the Tafel's law, overpotential increases when Tafel slope becomes larger [75]. Figure 5(b) compares the Tafel slopes of NPC-800, NPC-900, NPC-1000, and Pt/C samples. It demonstrates that the NPC-1000 sample has the smallest Tafel slope (64.9 $\mathrm{mV} \cdot$ decade $^{-1}$ ) in the high overpotential region among these electrocatalysts, which indicates that the specific activity of the NPC-1000 sample is higher than those of other synthesized samples and the commercial Pt/C electrocatalyst within the potential range investigated.

Most previous reports suggested that $900{ }^{\circ} \mathrm{C}$ was a better carbonization temperature than $1000{ }^{\circ} \mathrm{C}$ because it could lower the content of inactive pyrrolic nitrogen and achieve a relatively higher content of both pyridinic and graphitic nitrogen, while still ensuring a high conductivity by high temperature graphitization [76-79]. However, all electrochemical measurement results in this study demonstrate that the NPC-1000 electrocatalyst carbonized at $1000{ }^{\circ} \mathrm{C}$ has the best ORR performance although its graphitic-N and pyridinic-N contents are the lowest among these nitrogen-doped carbon sphere electrocatalysts investigated. This unusual result suggests that the ORR performance of an electrocatalyst may depend on other 
factors than the amount or species of its active sites.

Ning et al. [80] suggested that the ratio of pyridinic-N $\left(\mathrm{N}_{\mathrm{P}}\right)$ to graphitic-N $\left(\mathrm{N}_{\mathrm{G}}\right)$ could make a difference to its electrocatalytic performance. As a transfer electron descriptor of nitrogen-doped carbons in a reverse volcano manner, it was found that the oxygen catalytic performance would increase linearly with the increase of $\mathrm{N}_{\mathrm{P}}: \mathrm{N}_{\mathrm{G}}$ when $\mathrm{N}_{\mathrm{P}}: \mathrm{N}_{\mathrm{G}}$ was larger than 0.55 . The values of $\mathrm{N}_{\mathrm{P}}: \mathrm{N}_{\mathrm{G}}$ of these nitrogen-doped carbon sphere electrocatalysts investigated were all over 0.55 (see Table S3 in the ESM). However, the NPC-1000 electrocatalyst with the best ORR performance has the smallest $\mathrm{N}_{\mathrm{p}}: \mathrm{N}_{\mathrm{G}}$ value of $\sim 0.61$, while the NPC-800 electrocatalyst with the worst ORR performance has the largest $\mathrm{N}_{\mathrm{P}}: \mathrm{N}_{\mathrm{G}}$ value of $\sim 4.36$. Thus, the $\mathrm{N}_{\mathrm{P}}: \mathrm{N}_{\mathrm{G}}$ ratio effect could not explain the unusual result found in our study.

For these nitrogen-doped carbon sphere electrocatalysts, intrinsic carbon defects can not be responsible for their ORR performance differences either because no obvious difference exists in their Raman spectra (see Fig. 1(c)). The content of zinc also can not be responsible for their ORR performance differences. No matter the zinc contents are higher (NPC-800 and NPC-900 samples) or lower (NC-1000 sample without zinc), their ORR performances are lower than that of NPC-1000 sample. Furthermore, the ORR performance related to $\mathrm{Zn}$ atom was found to decrease very fast with its content drop as repored by Song et al. [28]. To get a similar ORR performance as the $\mathrm{Pt} / \mathrm{C}$ electrocatalyst, $\mathrm{Zn}$ content in their sample needed to reach $\sim 0.24 \mathrm{at} \%$. However, the $\mathrm{Zn}$ content in the NPC-1000 sample is only 0.03 at $\%$ as determined by ICP-AES, which is far lower than that of their sample. Thus, the ORR performance boosting mechanism in the NPC-1000 sample is not likely related to such a low residual $\mathrm{Zn}$ content in it.

For a typical four-electron pathway ORR in alkaline solution, the reduction reaction could be expressed as [35]:

$$
\begin{gathered}
\mathrm{O}_{2}+2 \mathrm{H}_{2} \mathrm{O}+4 \mathrm{e}^{-} \rightleftharpoons 4 \mathrm{OH}^{-}, \\
E^{0}=0.401 \mathrm{~V} \text { vs. SHE }
\end{gathered}
$$

From their $\mathrm{K}-\mathrm{L}$ plots, the two-electron transfer process is the major ORR process of NPC-800 and NPC-900 electrocatalysts, while the four-electron transfer process is the major ORR process of NPC-1000 electrocatalyst. Due to their similarities in structure, composition, and active sites (graphitic-N and pyridinic-N), it is not likely for NPC-1000 electrocatalyst to have a completely different electron transfer process than the NPC-800 and NPC-900 electrocatalysts. Actually, NPC-1000 electrocatalyst does have a slightly smaller electron transfer number $(\sim 3.6-4.0)$ than that of $\mathrm{Pt} / \mathrm{C}$ electrocatalyst $(\sim 3.8-4.0)$ as demonstrated in the rotating ring-disk electrode (RRDE) measurement (see Fig. S7(b) in the ESM), which suggests that it must have active sites that could only catalyze the two-electron transfer process.

The characterization results suggest that the main differences among these NPC- $t$ samples are their microstructures. From their SEM and TEM images (see Fig. 2), the number of graphited microflakes increases with the carbonization temperature and is the highest in NPC-1000 sample, which results in much more medium-sized pores and fine pores in NPC-1000 samples than in NPC-800 and NPC-900 samples as demonstrated by their BET analysis results. Thus, a space confinement mechanism that occurs mainly in mediumsized pores and fine pores of microflakes in NPC-1000 samples is proposed here to explain its superior ORR performance. In these NPC- $t$ samples, a large part of their active sites may not be active enough to catalyze the direct four-electron reduction of oxygen as shown in Reaction (1). However, they can be active enough to catalyze the two-electron oxygen reduction process to produce peroxide ions as shown in Reaction (2):

$$
\begin{gathered}
\mathrm{O}_{2}+\mathrm{H}_{2} \mathrm{O}+2 \mathrm{e}^{-} \rightleftharpoons \mathrm{HO}_{2}^{-}+\mathrm{OH}^{-}, \\
E^{0}=-0.076 \text { V vs. SHE }
\end{gathered}
$$

(Reaction 2)

Then, two reactions can happen with either a further two electron reduction as shown in Reaction (3):

$$
\begin{gathered}
\mathrm{HO}_{2}^{-}+\mathrm{H}_{2} \mathrm{O}+2 \mathrm{e}^{-} \rightleftharpoons 3 \mathrm{OH}^{-}, \\
E^{0}=0.878 \mathrm{~V} \text { vs. SHE }
\end{gathered}
$$

(Reaction 3)

or the disproportionation as shown in Reaction (4):

$$
2 \mathrm{HO}_{2}^{-} \rightleftharpoons 2 \mathrm{OH}^{-}+\mathrm{O}_{2} \quad \text { (Reaction 4) }
$$

Molecule dynamic simulation was adopted to explore the space confinement effect and examine how the pore size could affect it. To simply the simulation process, the pore shape was set as a cube, and peroxide ions were produced only from one surface of the cube. More details of the simulation process could be found in the ESM. Figure S8 in the ESM shows movements of peroxide ions confined in pores of sizes of 1,3 , and $10 \mathrm{~nm}$, respectively, obtained by the molecular dynamic simulation. Figures S9-S11 in the ESM show the representative trajectories of hydrogen and oxygen atoms of a selected single peroxide ion when the ion is 
confined in pores of sizes of 1,3 , and $10 \mathrm{~nm}$, respectively, and the green dash lines specify the collision region for oxygen atoms in these pores. When the position of an oxygen atom is outside the green dash line, the oxygen atom is considered to collide with the pore surface where ORR active sites are located. Higher collision frequency induces more effective reactions between intermediates and active sites, and subsequently results in their further reduction to have the desired four electron selectivity for ORR. Figure 6(a) shows the molecular dynamic simulation result on the relationship between the collision frequency (between peroxide ions and the pore surface) and the peroxide ion density, which demonstrates that the collision frequency increases linearly with the peroxide ion density increase. Figure $6(\mathrm{~b})$ shows the relationship between the collision frequency and the pore size by the molecular dynamic simulation, which demonstrates that the collision frequency increased linearly with the reciprocal of pore size from 10 to 3 $\mathrm{nm}$. With the further decrease of the pore size to $1 \mathrm{~nm}$, however, the collision frequency does not follow the linear relationship with the reciprocal of pore size and its increase became moderate.

When the pore size is large, the catalyst surface can be easily accessible for oxygen to generate intermediates. However, the collision frequency contributed from the space confinement effect is small because it is in direct proportion to the reciprocal of pore size. Thus, the further reduction of intermediates can not be dominant. When the pore size is very small ( $1 \mathrm{~nm}$ or less), the catalyst surface is difficult for oxygen to access to

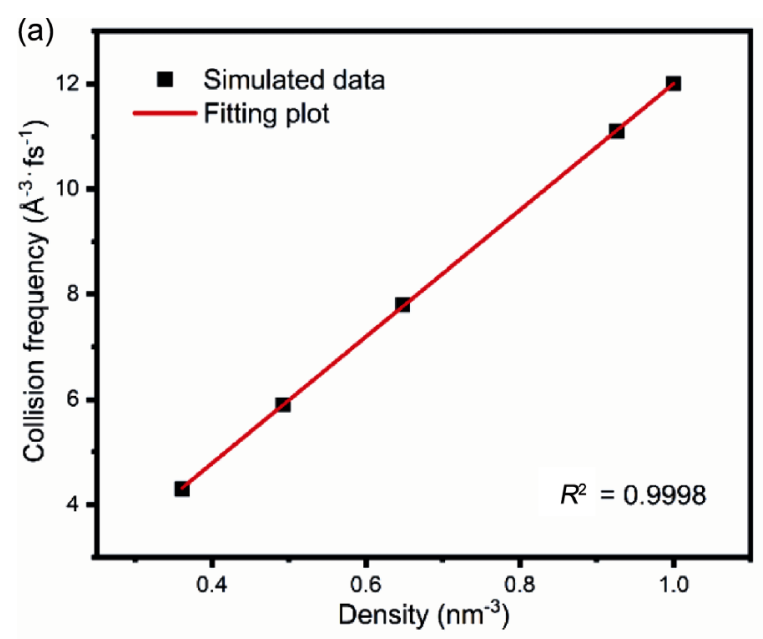

generate intermediates. Thus, the small intermediate density offsets the strong space confinement from the small pore size. So, there must be an optimized size range for the space confinement effect, which should be within several nanometers as suggested by the molecular dynamic simulation results. A mathematical exploration was also conducted as shown in the ESM, which clearly demonstrated that the findings from the molecular dynamic simulation can be generalized to pores with other shapes and peroxide production on all pore surfaces.

Due to the existence of rich medium-sized pores and fine pores in microflakes of NPC-1000 electrocatalyst, peroxide ions produced in the first two electron reduction process are confined in the highly porous microflakes, where large surface areas provide plenty of active sites for ORR. Thus, as demonstrated above, the space confinement of peroxide ions in these medium-sized pores and fine pores increases the chance for peroxide ions to have contact with active sites in NPC-1000 electrocatalyst and react with electrons for its further two-electron reduction as Reaction (3) rather than its disproportionation as Reaction (4). Therefore, NPC-1000 electrocatalyst finally demonstrates the desirable overall four-electron ORR transfer process through the two-step oxygen reduction process. Our work suggests that the increase of active sites is not the only approach for the enhancement of the ORR activity in electrocatalysts, and a careful modulation and control of microstructures can also be effective to create ORR electrocatalysts with good performances.

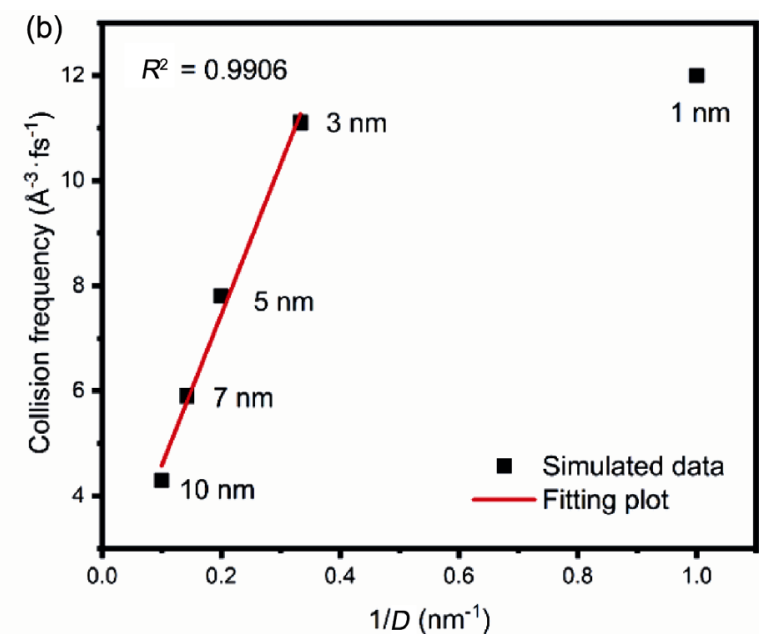

Fig. 6 (a) Collision frequency vs. peroxide ion density and (b) collision frequency vs. pore size obtained by the molecular dynamic (MD) simulation. 


\section{Conclusions}

In summary, a low-cost, highly porous nitrogen-doped carbon sphere PGM-free electrocatalyst was synthesized with widely available raw materials by a simple and robust carbonization process on biomass carbon spheres mixed with urea and zinc chloride in $\mathrm{N}_{2}$ atmosphere at $1000{ }^{\circ} \mathrm{C}$ for $2 \mathrm{~h}$. It demonstrates a superior or at least comparable ORR activity as the commercial $\mathrm{Pt} / \mathrm{C}$ electrocatalyst with a better longterm stability and methanol tolerance. More importantly, it is demonstrated experimentally that more active sites do not always ensure a better ORR performance for electrocatalysts, while the space confinement effect from their specific microstructures may be crucial for their overall ORR performances through the change of reaction process. This finding on space confinement effect from microstructure sheds light on design of high-performance ORR electrocatalysts, and may find more applications in the design of novel catalysts for various technical fields.

\section{Acknowledgements}

This study was supported by the National Natural Science Foundation of China (Grant Nos. 51672283 and 51902271), the Fundamental Research Funds for the Central Universities (Grant Nos. A1920502051907-15, 2682020CX07, and 2682020CX08), Sichuan Science and Technology Program (Grant Nos. 2020YJ0259 and 2020YJ0072), Shandong Provincial Natural Science Foundation (Grant No. ZR2019MEM045), Joint Fund between Shenyang National Laboratory for Materials Science and State Key Laboratory of Advanced Processing and Recycling of Nonferrous Metals (Grant No. 18LHPY009), and Liaoning Baiqianwan Talents Program.

\section{Electronic Supplementary Material}

Supplementary material is available in the online version of this article at https://doi.org/10.1007/s40145-021-0466-1.

\section{References}

[1] Dincer I, Acar C. A review on clean energy solutions for better sustainability. Int J Energy Res 2015, 39: 585-606.

[2] Ehsani M, Gao Y, Longo S, et al. Modern Electric, Hybrid Electric, and Fuel Cell Vehicles. Boca Raton (USA): CRC
Press, 2018.

[3] Debe MK. Electrocatalyst approaches and challenges for automotive fuel cells. Nature 2012, 486: 43-51.

[4] Wang XQ, Li ZJ, Qu YT, et al. Review of metal catalysts for oxygen reduction reaction: From nanoscale engineering to atomic design. Chem 2019, 5: 1486-1511.

[5] Han JX, Bian JJ, Sun CW. Recent advances in single-atom electrocatalysts for oxygen reduction reaction. Research 2020, 2020: 9512763.

[6] Sun CW, Alonso JA, Bian JJ. Recent advances in perovskite-type oxides for energy conversion and storage applications. Adv Energy Mater 2021, 11: 2000459.

[7] Yang LJ, Shui JL, Du L, et al. Carbon-based metal-free ORR electrocatalysts for fuel cells: Past, present, and future. Adv Mater 2019, 31: 1804799.

[8] Martinez U, Komini Babu S, Holby EF, et al. Progress in the development of Fe-based PGM-free electrocatalysts for the oxygen reduction reaction. Adv Mater 2019, 31: 1806545 .

[9] Gong YD, Ding W, Li ZP, et al. Inverse spinel cobalt-iron oxide and $\mathrm{N}$-doped graphene composite as an efficient and durable bifuctional catalyst for $\mathrm{Li}-\mathrm{O}_{2}$ batteries. ACS Catal 2018, 8: 4082-4090.

[10] Han JX, Bao HL, Wang JQ, et al. 3D N-doped ordered mesoporous carbon supported single-atom Fe-N-C catalysts with superior performance for oxygen reduction reaction and zinc-air battery. Appl Catal B: Environ 2021, 280: 119411.

[11] Sun CW, Li F, Ma C, et al. Graphene- $\mathrm{Co}_{3} \mathrm{O}_{4}$ nanocomposite as an efficient bifunctional catalyst for lithium-air batteries. J Mater Chem A 2014, 2: 7188-7196.

[12] Liu R, Wu D, Feng X, et al. Nitrogen-doped ordered mesoporous graphitic arrays with high electrocatalytic activity for oxygen reduction. Angew Chem Int Ed 2010, 49: 2565-2569.

[13] Chen S, Bi JY, Zhao Y, et al. Nitrogen-doped carbon nanocages as efficient metal-free electrocatalysts for oxygen reduction reaction. Adv Mater 2012, 24: 5593-5597.

[14] Silva R, Voiry D, Chhowalla M, et al. Efficient metal-free electrocatalysts for oxygen reduction: Polyaniline-derived N- and O-doped mesoporous carbons. J Am Chem Soc 2013, 135: 7823-7826.

[15] Zhang P, Sun F, Xiang ZH, et al. ZIF-derived in situ nitrogen-doped porous carbons as efficient metal-free electrocatalysts for oxygen reduction reaction. Energy Environ Sci 2014, 7: 442-450.

[16] Zhong HX, Wang J, Zhang YW, et al. ZIF-8 derived graphene-based nitrogen-doped porous carbon sheets as highly efficient and durable oxygen reduction electrocatalysts. Angew Chem Int Ed 2014, 53: 14235-14239.

[17] Yu HJ, Shang L, Bian T, et al. Nitrogen-doped porous carbon nanosheets templated from $\mathrm{g}-\mathrm{C}_{3} \mathrm{~N}_{4}$ as metal-free electrocatalysts for efficient oxygen reduction reaction. Adv Mater 2016, 28: 5080-5086.

[18] Paul R, Zhu L, Chen H, et al. Recent advances in carbonbased metal-free electrocatalysts. Adv Mater 2019, 31: 1806403

[19] Gong KP, Du F, Xia ZH, et al. Nitrogen-doped carbon nanotube arrays with high electrocatalytic activity for 
oxygen reduction. Science 2009, 323: 760-764.

[20] Xing T, Zheng Y, Li LH, et al. Observation of active sites for oxygen reduction reaction on nitrogen-doped multilayer graphene. ACS Nano 2014, 8: 6856-6862.

[21] Rao CV, Cabrera CR, Ishikawa Y. In search of the active site in nitrogen-doped carbon nanotube electrodes for the oxygen reduction reaction. $J$ Phys Chem Lett 2010, 1: 2622-2627.

[22] Guo D, Shibuya R, Akiba C, et al. Active sites of nitrogen-doped carbon materials for oxygen reduction reaction clarified using model catalysts. Science 2016, 351: 361-365.

[23] Cui XY, Yang SB, Yan XX, et al. Pyridinic-nitrogendominated graphene aerogels with $\mathrm{Fe}-\mathrm{N}-\mathrm{C}$ coordination for highly efficient oxygen reduction reaction. Adv Funct Mater 2016, 26: 5708-5717.

[24] He WH, Jiang $\mathrm{CH}$, Wang JB, et al. High-rate oxygen electroreduction over graphitic-N species exposed on $3 \mathrm{D}$ hierarchically porous nitrogen-doped carbons. Angew Chem Int Ed 2014, 53: 9503-9507.

[25] Niu WH, Li LG, Liu XJ, et al. Mesoporous N-doped carbons prepared with thermally removable nanoparticle templates: An efficient electrocatalyst for oxygen reduction reaction. J Am Chem Soc 2015, 137: 5555-5562.

[26] Yang HB, Miao JW, Hung SF, et al. Identification of catalytic sites for oxygen reduction and oxygen evolution in N-doped graphene materials: Development of highly efficient metal-free bifunctional electrocatalyst. Sci $A d v$ 2016, 2: e1501122.

[27] Lin YX, Yang L, Zhang YK, et al. Defective carbon-CoP nanoparticles hybrids with interfacial charges polarization for efficient bifunctional oxygen electrocatalysis. $A d v$ Energy Mater 2018, 8: 1703623.

[28] Song P, Luo M, Liu XZ, et al. Zn single atom catalyst for highly efficient oxygen reduction reaction. Adv Funct Mater 2017, 27: 1700802.

[29] Li J, Chen SG, Yang N, et al. Ultrahigh-loading zinc single-atom catalyst for highly efficient oxygen reduction in both acidic and alkaline media. Angew Chem Int Ed 2019, 58: 7035-7039.

[30] Zhuang TT, Pang YJ, Liang ZQ, et al. Copper nanocavities confine intermediates for efficient electrosynthesis of C3 alcohol fuels from carbon monoxide. Nat Catal 2018, 1: 946-951.

[31] Sen S, Liu D, Palmore GTR. Electrochemical reduction of $\mathrm{CO}_{2}$ at copper nanofoams. ACS Catal 2014, 4: 3091-3095.

[32] Lu Q, Rosen J, Jiao F. Nanostructured metallic electrocatalysts for carbon dioxide reduction. Chem CatChem 2015, 7: 38-47.

[33] Ma M, Djanashvili K, Smith WA. Controllable hydrocarbon formation from the electrochemical reduction of $\mathrm{CO}_{2}$ over Cu nanowire arrays. Angew Chem Int Ed 2016, 55: 6680-6684.

[34] Hursán D, Samu AA, Janovák L, et al. Morphological attributes govern carbon dioxide reduction on $\mathrm{N}$-doped carbon electrodes. Joule 2019, 3: 1719-1733.

[35] Ge XM, Sumboja A, Wuu D, et al. Oxygen reduction in alkaline media: From mechanisms to recent advances of catalysts. ACS Catal 2015, 5: 4643-4667.

[36] Choi CH, Kim M, Kwon HC, et al. Tuning selectivity of electrochemical reactions by atomically dispersed platinum catalyst. Nat Commun 2016, 7: 10922.

[37] Melchionna M, Fornasiero P, Prato M. The rise of hydrogen peroxide as the main product by metal-free catalysis in oxygen reductions. Adv Mater 2019, 31: e1802920.

[38] Ai KL, Liu YL, Ruan CP, et al. $\mathrm{Sp}^{2} \mathrm{C}$-dominant N-doped carbon sub-micrometer spheres with a tunable size: A versatile platform for highly efficient oxygen-reduction catalysts. Adv Mater 2013, 25: 998-1003.

[39] Wang SG, Cui ZT, Qin JW, et al. Thermally removable in situ formed $\mathrm{ZnO}$ template for synthesis of hierarchically porous $\mathrm{N}$-doped carbon nanofibers for enhanced electrocatalysis. Nano Res 2016, 9: 2270-2283.

[40] Liang CD, Hong KL, Guiochon GA, et al. Synthesis of a large-scale highly ordered porous carbon film by selfassembly of block copolymers. Angew Chem Int Ed 2004, 43: 5785-5789.

[41] Yu ZL, Li GC, Fechler N, et al. Polymerization under hypersaline conditions: A robust route to phenolic polymerderived carbon aerogels. Angew Chem Int Ed 2016, 55: 14623-14627.

[42] Zhang JN, Song Y, Kopeć M, et al. Facile aqueous route to nitrogen-doped mesoporous carbons. J Am Chem Soc 2017, 139: 12931-12934.

[43] Zhang HW, Huang XD, Noonan O, et al. Tailored yolk-shell Sn@C nanoboxes for high-performance lithium storage. Adv Funct Mater 2017, 27: 1606023.

[44] Chen HJ, Wei HM, Fu N, et al. Nitrogen-doped porous carbon using $\mathrm{ZnCl}_{2}$ as activating agent for high-performance supercapacitor electrode materials. J Mater Sci 2018, 53: 2669-2684.

[45] Ji LW, Zhang XW. Generation of activated carbon nanofibers from electrospun polyacrylonitrile-zinc chloride composites for use as anodes in lithium-ion batteries. Electrochem Commun 2009, 11: 684-687.

[46] Liu SZ, Peng WC, Sun HQ, et al. Physical and chemical activation of reduced graphene oxide for enhanced adsorption and catalytic oxidation. Nanoscale 2014, 6: 766-771.

[47] Wang N, Li TF, Song Y, et al. Metal-free nitrogen-doped porous carbons derived from pomelo peel treated by hypersaline environments for oxygen reduction reaction. Carbon 2018, 130: 692-700.

[48] Ravikovitch PI, Haller GL, Neimark AV. Density functional theory model for calculating pore size distributions: Pore structure of nanoporous catalysts. Adv Colloid Interface Sci 1998, 76-77: 203-226.

[49] Bard AJ, Faulkner LR. Electrochemical Methods: Fundamentals and Applications. New York: Wiley, 2001: 331-367.

[50] Liang $\mathrm{Y}$, Li $\mathrm{Y}$, Wang $\mathrm{H}$, et al. $\mathrm{Co}_{3} \mathrm{O}_{4}$ nanocrystals on graphene as a synergistic catalyst for oxygen reduction reaction. Nat Mater 2011, 10: 780-786.

[51] Yu HJ, Shang L, Bian T, et al. Nitrogen-doped porous carbon nanosheets templated from $\mathrm{g}-\mathrm{C}_{3} \mathrm{~N}_{4}$ as metal-free electrocatalysts for efficient oxygen reduction reaction. Adv Mater 2016, 28: 5080-5086.

[52] Tafel J. Über die Polarisation bei kathodischer Wasserstoffentwicklung. Z Phys Chem 1905, 50: 641-712.

[53] Jia Z, Yin G, Zhang J. Rotating ring-disk electrode method. In: Rotating Electrode Methods and Oxygen Reduction 
Electrocatalysts. Xing W, Yin G, Zhang J, Eds. Amsterdam: Elsevier, 2014: 199-229.

[54] Plimpton S. Fast parallel algorithms for short-range molecular dynamics. J Comput Phys 1995, 117: 1-19.

[55] Stukowski A. Visualization and analysis of atomistic simulation data with OVITO-the Open Visualization Tool. Modelling Simul Mater Sci Eng 2009, 18: 015012.

[56] Pimenta MA, Dresselhaus G, Dresselhaus MS, et al. Studying disorder in graphite-based systems by Raman spectroscopy. Phys Chem Chem Phys 2007, 9: 1276-1291.

[57] Ferrari AC, Robertson J. Interpretation of Raman spectra of disordered and amorphous carbon. Phys Rev B 2000, 61: 14095-14107.

[58] O'Neil MJ. The Merck Index: An Encyclopedia of Chemicals, Drugs, and Biologicals. Cambridge: RSC Publishing, 2013.

[59] Molina-Sabio M, Rodriguez-Reinoso F. Role of chemical activation in the development of carbon porosity. Colloid Surface A 2004, 241: 15-25.

[60] Wang JP, Han GK, Wang LG, et al. ZIF-8 with ferrocene encapsulated: A promising precursor to single-atom $\mathrm{Fe}$ embedded nitrogen-doped carbon as highly efficient catalyst for oxygen electroreduction. Small 2018, 14: 1704282.

[61] Guo C, Tong X, Guo XY. Nitrogen-doped mesoporous network-like carbon as an efficient metal-free electrocatalyst for oxygen reduction reaction. Int J Hydrogen Energy 2016, 41: 22941-22951.

[62] Hu CG, Dai LM. Multifunctional carbon-based metal-free electrocatalysts for simultaneous oxygen reduction, oxygen evolution, and hydrogen evolution. Adv Mater 2017, 29: 1604942.

[63] Liu SW, Zhang HM, Zhao Q, et al. Metal-organic framework derived nitrogen-doped porous carbon@graphene sandwich-like structured composites as bifunctional electrocatalysts for oxygen reduction and evolution reactions. Carbon 2016, 106: 74-83.

[64] Wang Y, Liu HY, Wang K, et al. 3D interconnected hierarchically porous $\mathrm{N}$-doped carbon with $\mathrm{NH}_{3}$ activation for efficient oxygen reduction reaction. Appl Catal B: Environ 2017, 210: 57-66.

[65] Lv Q, Si W, He J, et al. Selectively nitrogen-doped carbon materials as superior metal-free catalysts for oxygen reduction. Nat Commun 2018, 9: 3376.

[66] Jiang H, Gu JX, Zheng XS, et al. Defect-rich and ultrathin $\mathrm{N}$ doped carbon nanosheets as advanced trifunctional metal-free electrocatalysts for the ORR, OER and HER. Energy Environ Sci 2019, 12: 322-333.

[67] $\mathrm{Du} \mathrm{C}$, Liu XL, Ye GH, et al. Balancing the micromesoporosity for activity maximization of $\mathrm{N}$-doped carbonaceous electrocatalysts for the oxygen reduction reaction. ChemSusChem 2019, 12: 1017-1025.

[68] Antolini E, Lopes T, Gonzalez ER. An overview of platinum-based catalysts as methanol-resistant oxygen reduction materials for direct methanol fuel cells. $J$ Alloys Compd 2008, 461: 253-262.

[69] Osmieri L, Escudero-Cid R, Monteverde Videla AHA, et al. Performance of a Fe-N-C catalyst for the oxygen reduction reaction in direct methanol fuel cell: Cathode formulation optimization and short-term durability. Appl Catal B:
Environ 2017, 201: 253-265.

[70] Xu XL, Xia ZX, Zhang XM, et al. Atomically dispersed $\mathrm{Fe}-\mathrm{N}-\mathrm{C}$ derived from dual metal-organic frameworks as efficient oxygen reduction electrocatalysts in direct methanol fuel cells. Appl Catal B: Environ 2019, 259: 118042.

[71] Liu LZ, Zeng G, Chen JX, et al. N-doped porous carbon nanosheets as $\mathrm{pH}$-universal ORR electrocatalyst in various fuel cell devices. Nano Energy 2018, 49: 393-402.

[72] Matter PH, Zhang L, Ozkan US. The role of nanostructure in nitrogen-containing carbon catalysts for the oxygen reduction reaction. $J$ Catal 2006, 239: 83-96.

[73] Zhang JT, Zhao ZH, Xia ZH, et al. A metal-free bifunctional electrocatalyst for oxygen reduction and oxygen evolution reactions. Nat Nanotechnol 2015, 10: 444-452.

[74] Vago ER, Calvo EJ. Oxygen electro-reduction on iron oxide electrodes: III. Heterogeneous catalytic $\mathrm{H}_{2} \mathrm{O}_{2}$ decomposition. J Electroanal Chem 1995, 388: 161-165.

[75] Zeng HJ, Wang W, Li J, et al. In situ generated dual-template method for $\mathrm{Fe} / \mathrm{N} / \mathrm{S}$ Co-doped hierarchically porous honeycomb carbon for high-performance oxygen reduction. ACS Appl Mater Interfaces 2018, 10: 8721-8729.

[76] Zhang X, Yu D, Zhang Y, et al. Nitrogen- and sulfur-doped carbon nanoplatelets via thermal annealing of alkaline lignin with urea as efficient electrocatalysts for oxygen reduction reaction. $R S C A d v 2016,6$ : 104183-104192.

[77] Guo CZ, Hu R, Liao WL, et al. Protein-enriched fish "biowaste" converted to three-dimensional porous carbon nano-network for advanced oxygen reduction electrocatalysis. Electrochimica Acta 2017, 236: 228-238.

[78] Yang XX, Li K, Cheng DM, et al. Nitrogen-doped porous carbon: Highly efficient trifunctional electrocatalyst for oxygen reversible catalysis and nitrogen reduction reaction. J Mater Chem A 2018, 6: 7762-7769.

[79] Ye WY, Tang JH, Wang YJ, et al. Hierarchically structured carbon materials derived from lotus leaves as efficient electrocatalyst for microbial energy harvesting. Sci Total Environ 2019, 666: 865-874.

[80] Ning XM, Li YH, Ming JY, et al. Electronic synergism of pyridinic- and graphitic-nitrogen on N-doped carbons for the oxygen reduction reaction. Chem Sci 2019, 10: 1589-1596.

Open Access This article is licensed under a Creative Commons Attribution 4.0 International License, which permits use, sharing, adaptation, distribution and reproduction in any medium or format, as long as you give appropriate credit to the original author(s) and the source, provide a link to the Creative Commons licence, and indicate if changes were made.

The images or other third party material in this article are included in the article's Creative Commons licence, unless indicated otherwise in a credit line to the material. If material is not included in the article's Creative Commons licence and your intended use is not permitted by statutory regulation or exceeds the permitted use, you will need to obtain permission directly from the copyright holder.

To view a copy of this licence, visit http://creativecommons.org/licenses/by/4.0/. 